\title{
Percepções da Morte entre os Estudantes de Medicina
}

Perceptions of Death among Medical Students

Las Percepciones de Muerte entre los Estudiantes de Medicina

Raíssa Ruperto Souza das Chagas ${ }^{1}$

Cecília Frazão Castro ${ }^{2}$

Vanessa Késsia Silva Teixeira de Moura ${ }^{3}$

Jairo Calado Cavalcante ${ }^{4}$

Sandra Lopes Cavalcanti ${ }^{5}$

Daniel Antunes Freitas ${ }^{6}$

\section{Resumo}

Objetivo: Estudar a percepção de universitários de medicina sobre a morte e o morrer. Método: Estudo observacional, transversal, quantitativo, realizado entre março de 2015 a março de 2016, com 248 estudantes de medicina da Universidade Federal de Alagoas. O estudo usou questionário estruturado, aplicado aos acadêmicos de todos os períodos do curso. Os dados foram armazenados e analisados no programa Excel®. Para análise foram criados dois grupos: ciclo teórico e ciclo prático do curso. Resultados: Do total de discentes estudados, $44,35 \%$ teve contato com a morte durante a graduação. Em relação à preparação para lidar com a morte, entre os alunos do ciclo teórico, 59,32\% afirmou não estar preparado para isso e $44 \%$ respondeu raramente ter participado de discussões sobre a terminalidade da vida durante o curso. Além disso, $90,72 \%$ dos estudantes afirmaram que mudaram em algum nível, a sua percepção em relação à morte na graduação. Conclusão: Os dados mostram que os estudantes não são preparados para lidar com a morte durante a graduação e sugere-se a

${ }^{1}$ Discente do curso de graduação em Medicina pela Universidade Federal de Alagoas (UFAL). Autora correspondente: Av. Lourival Melo Mota, s/n. Tabuleiro dos Martins. Maceió, Alagoas, Brasil. 57072900. E-mail: raissa.ruperto@gmail.com

${ }^{2,3}$ Discente do curso de graduação em Medicina pela Universidade Federal de Alagoas (UFAL).

${ }^{4}$ Médico. Docente da UFAL.

${ }^{5}$ Psicóloga Clínica. Docente da UFAL.

${ }^{6}$ Doutor em Saúde Coletiva pela Universidade Estadual de Montes Claros. 
introdução da temática de forma sistemática durante o curso para contribuir no melhor entendimento da morte e do morrer.

\section{Descritores: Percepção; Morte;}

\section{Estudantes de Medicina.}

\section{Abstract}

Objective: To study the perception of medical students about death and dying. Methods: Observational, crosssectional, quantitative, conducted from March 2015 to March 2016, with 248 medical students of the Federal University of Alagoas. The study used a structured questionnaire, applied to scholars from all periods of the course. Data were stored and analyzed in Excel®. For analysis were created two groups: theoretical and practical cycle course cycle. Results: Of the studied students, $44.35 \%$ had contact with death during graduation. Regarding preparation to deal with death, among the students of the theoretical cycle, $59.32 \%$ said he was not prepared for it and $44 \%$ said rarely have participated in discussions about the terminal illness of life during the course. Conclusion: The data show that students are not prepared to deal with death during graduation and suggests the introduction of the subject in a systematic way during the course to contribute to the better understanding of death and dying.

\section{Descriptors: Perception; Death;}

\section{Students Medical.}

\section{Resumen}

Objetivo: Para el estudio de la percepción de los estudiantes de medicina sobre la muerte y el morir. Métodos: Los métodos de observación, en sección transversal, cuantitativo, realizado a partir de marzo 2015 a marzo 2016, con 248 estudiantes de medicina de la Universidad Federal de Alagoas. El estudio utilizó un cuestionario estructurado, aplicado a los estudiosos de todas las épocas del curso. Los datos fueron almacenados y analizados en Excel®. Para el análisis se crearon dos grupos: ciclo supuesto ciclo teórico y práctico. Resultados: De los alumnos estudiados, $44.35 \%$ tenían contacto con la muerte durante la graduación. En cuanto a la preparación para hacer frente a la muerte, entre los alumnos del ciclo teórico, 59.32\% dijo que no estaba preparado para ello y el $44 \%$ dijo que rara vez han participado 
en las discusiones sobre la enfermedad terminal de la vida durante el curso. Conclusión: Los datos muestran que los estudiantes no están preparados para hacer frente a la muerte durante la graduación y sugiere la introducción del tema de manera sistemática durante el curso para contribuir a la mejor comprensión de la muerte y el morir.

\section{Descriptores: Percepción; Muerte;} Estudiantes de Medicina.

\section{Introdução}

A morte é um evento biológico natural e inevitável da vida humana. A palavra morte, do latim mors é caracterizada pela incerteza, pelo mistério e, consequentemente, pelo medo daquilo que não se conhece, pois os que a experimentaram não tiveram chances de relatá-la aos que aqui ficaram, desafiando assim diversas culturas ao longo da história a buscarem respostas nos mitos, nas religiões, na arte e na filosofia, a fim de minimizar a angústia gerada pela morte ${ }^{(1)}$.

Ao longo da história, a morte teve papel importante nas sociedades. $\mathrm{Na}$ Mesopotâmia, a sociedade sepultava seus mortos com bastante zelo, de modo que juntamente com o corpo eram postos vários objetos que marcaram a identidade pessoal e familiar da pessoa morta, garantido que nada faltaria na transição da mesma do mundo da vida para o mundo da morte. Desse modo, para os mesopotâmios a morte significava passagem.

Já os gregos tinham a prática cultural de cremar os corpos dos mortos, com intuito de marcar a nova condição existencial destes, a condição social de mortos. Contudo, havia dois tipos de mortos: os mortos comuns e anônimos eram cremados e enterrados coletivamente em valas, pois eram vistos como simples mortais; e os mortos heróis falecidos eram levados à pira crematória, reservada para os grandes heróis, na cerimônia da bela morte, que na visão dos gregos tornava imortal o morto.

A Idade Média foi marcada por dois principais momentos, pela Alta Idade Médica na qual as pessoas tinham uma concepção mais natural sobre a morte. A ascensão da Igreja Católica, na Baixa Idade Média, torna a morte como um sinônimo de tudo que pode ser considerado ruim, tendo como representação uma caveira com uma foice $^{(2)}$. Nesse período, a morte era vista como uma punição, caso o indivíduo tenha sido ruim iria para o inferno, e 
caso fosse bom iria para o Reino dos Céus. Esse conceito auxiliou a tornar a morte um medo, e um receio ao esperar o que vai acontecer no futuro.

Com o passar dos séculos, a morte continua sendo um tabu para a maioria das culturas que a tratam distante com medo de encará-la.

Presente no cotidiano dos profissionais de saúde, a morte compõe o processo de desenvolvimento humano $^{(4)}$. $\mathrm{Na}$ atualidade, a morte ocorre, principalmente, nos hospitais, sendo, muitas vezes, assistida pelos trabalhadores da saúde, e até por estudantes da área de saúde, que vivenciam o conflito de ter a responsabilidade pelo cuidado ao paciente em processo de morte e a vontade de curar e restabelecer a saúde de todos como algo inevitável do cotidiano $^{(5)}$.

Os profissionais que trabalham em hospital geralmente tem um enfoque muito empenhado no processo de cura do paciente. O paciente cuja doença não pode ser curada é visto como um fracasso para os profissionais e para estas instituições. O que importa é vencer a doença a qualquer custo. $\mathrm{O}$ objeto de trabalho do médico, em algumas situações, parece que passou a ser a doença; logo, vencer a morte é vencer um adversário ${ }^{(6)}$. Diante dessa realidade os trabalhadores da área da saúde tornam-se mais vulneráveis aos sentimentos que se relacionam a finitude da vida ${ }^{(7)}$.

Nesse processo de formação profissional, no contexto da graduação em Medicina, ressalta-se que a educação formal para morte poderia transformar-se em um espaço de construção de novos sentidos e novas maneiras de intervenção sobre a realidade, além de possibilitar a superação da alienação e um desenvolvimento humano mais pleno ${ }^{(8)}$.

As Instituições de Ensino Superior devem aprofundar as discussões sobre morte e religião, infância/adolescência, velhice e processo de luto, de forma contextualizada com a realidade ${ }^{(9)}$. E as instituições de graduação em saúde precisam, também, repensar a formação do estudante de Medicina diante da temática cessação da vida, como uma atividade inicial, que abra possibilidades para que ele, em sua prática, possa aprender a buscar ferramentas para prestar assistência com qualidade $^{(10)}$.

Dessa maneira, conhecer as experiências e o quanto os estudantes de Medicina estão preparados em relação à 
temática da morte e do morrer é poder contextualizar o universo de valores e atitudes em que estão inseridos ${ }^{(11)}$, e assim, proporcionar um processo de ensino-aprendizagem mais próximo da realidade dos acadêmicos.

Esta pesquisa foi planejada para estudar a percepção de universitários de medicina perante a morte e o morrer, bem como identificar as implicações da morte do paciente na atuação do estudante, identificar a frequência do contato do estudante de medicina com a morte, estudar o preparo dos estudantes perante a morte e identificar a participação em discussões sobre terminalidade da vida na graduação.

\section{Método}

Trata-se de um estudo observacional, transversal, de abordagem quantitativa. A amostra foi constituída por 248 alunos, distribuídos em todos os períodos do curso, selecionados de forma aleatória. Utilizou-se um questionário estruturado, contendo 16 questões, abertas e fechadas, sobre o tema, como: já ter vivenciado a morte durante a graduação, presença de discussões sobre a terminalidade da vida no curso, preparação para o enfrentamento da morte; sendo aplicado pelas discentes responsáveis ou com a colaboração dos docentes, entre os meses de outubro de 2015 a fevereiro de 2016, em sala de aula, ou nos intervalos entre as aulas, e estágios, no caso dos estudantes que estão no internato. Esclarecimentos de eventuais dúvidas eram sanadas com os aplicadores do questionário.

Para análise dos questionários, os estudantes foram divididos em duas categorias: ciclo teórico, que constitui os dois primeiros anos do curso, e ciclo prático, juntamente com o estágio supervisionado, que constituem os quatro anos restantes. Os dados foram armazenados em banco de dados no programa Excel, de acordo com as perguntas do questionário aplicado, e os grupos separados em dois grandes grupos, o primeiro contendo os dados dos estudantes do ciclo básico e o segundo grupo com estudantes do ciclo clínico e internato.

Esta pesquisa obteve a aprovação do Comitê de Ética em Pesquisa (CEP), localizado na UFAL, com número de processo 45959415.3.0000.5013.

\section{Resultados}

Os estudantes de medicina pesquisados constituem um grupo em 
que o sexo feminino é predominante $(57,26 \%)$ e faixa etária de 21 a 25 anos $(56,33 \%)$. Sendo que, $59,32 \%$ dos estudantes do ciclo teórico do curso se consideram despreparados para lidar com a morte dos pacientes. Os alunos dos quatro últimos anos atuam diretamente com os pacientes, e 46,51\% desses, afirmam que ainda se sentem despreparados perante o falecimento de um paciente. Apenas um estudante não respondeu essa pergunta.

\section{Tabela 1: Distribuição dos estudantes segundo preparo e período do curso para enfrentar a morte}

\begin{tabular}{lccc}
\hline PREPARO & \multicolumn{2}{c}{ CICLO } & TOTAL \\
\cline { 2 - 4 } & Teórico & Prático e estágio \\
\hline Totalmente preparado & $09(7,63 \%)$ & $04(3,10 \%)$ & 13 \\
Preparado & $39(33,05 \%)$ & $65(50,39 \%)$ & 104 \\
Despreparado & $70(59,32 \%)$ & $60(46,51 \%)$ & 130 \\
\hline TOTAL & 118 & 129 & 247 \\
\hline
\end{tabular}

O contato com a morte pelo estudante de Medicina acontece ao longo do curso, na rotina em ambulatórios, enfermarias e emergências. $\mathrm{Na}$ Tabela 2, é evidenciado que $73,95 \%$ dos estudantes dos primeiros anos de curso não têm contato com a morte na graduação, e estudantes do $5^{\circ}$ ao $12^{\circ}$ períodos tem uma convivência maior com esse fato, apesar de ser muito variável a periodicidade desse contato.

Tabela 2: Contato com a morte na graduação.

\begin{tabular}{lrrc}
\hline CONTATO & \multicolumn{2}{c}{ CICLOS } & TOTAL \\
\hline \multirow{3}{*}{ Inexistente } & \multicolumn{1}{c}{ Teórico } & Prático e estágio & \\
\cline { 2 - 4 } Mensalmente & $88(73,95 \%)$ & $34(26,36 \%)$ & 122 \\
Semestralmente & $12(10,08 \%)$ & $43(33,33 \%)$ & 55 \\
Anualmente & $10(8,40 \%)$ & $33(25,58 \%)$ & 43 \\
TOTAL & $09(7,56 \%)$ & $19(14,73 \%)$ & 28 \\
\hline
\end{tabular}


Dos 248 estudantes, $110(44,35 \%)$ tiveram contato com a morte durante a graduação. Os que já tiveram a vivência, ao serem questionados se algo a mudou na atuação deles como acadêmicos, $58 \%$ responderam que sim e escreveram afirmações como:

Passei a considerar mais a dor do paciente e aliviar o sofrimento, mesmo em situação de morte iminente (estudante 1);

Me senti mais incapaz, mas ao mesmo tempo me estimulou a buscar mais conhecimento sobre o assunto (estudante 2);

Pude perceber que a morte às vezes é necessária (estudante 3 ).
Foi questionado se a graduação tinha oferecido alguma mudança na visão da morte e do morrer sobre a percepção concebida anteriormente, $24,19 \%$ dos alunos afirmaram terem mudado muito a visão, $31,85 \%$ terem mudado razoavelmente, essas afirmações dos estudantes tanto do ciclo teórico, do ciclo prático e do internado, afirmaram ter tido alguma mudança na percepção da morte, seja essa mudança, pouca, razoável ou muita (Tabela 3). Dos estudantes que não tiveram nenhuma alteração dessa visão, que compõe 9,27\% dos alunos, a grande maioria está no ciclo teórico, 69,46\%.

\section{Tabela 3: Frequência da participação dos estudantes em discussões sobre a terminalidade durante a graduação.}

\begin{tabular}{cccc}
\hline FREQUÊNCIA & \multicolumn{2}{c}{ CICLOS } & TOTAL \\
\cline { 2 - 4 } & Teórico & Prático e Estágio & \\
\hline Nunca & $25(21,01 \%)$ & $31(24,03 \%)$ & 56 \\
Raramente & $54(45,38 \%)$ & $56(43,41 \%)$ & 110 \\
Ocasionalmente & $38(31,93 \%)$ & $37(28,68 \%)$ & 75 \\
Frequentemente & $02(1,68 \%)$ & $05(3,88 \%)$ & 7 \\
\hline TOTAL & 119 & 129 & 248 \\
\hline
\end{tabular}

Quando questionados sobre a tipo de discussão no curso (Ciclo participação em discussões sobre a Teórico $=45,38 \%$ / Ciclo terminalidade da vida durante a Prático=43.41\%). graduação (tabela 3), a maior parte do grupo respondeu raramente ter tido esse

\section{Discussão}


O ciclo teórico do curso de Medicina ocorre nos dois primeiros anos, que se divide em quatro períodos, e se propõe a inserir o aluno às bases morfofuncionais do corpo humano, como fisiologia, biologia celular, anatomia, bioquímica, histologia e embriologia. Aliado a isso, são ministradas aulas de Saúde e Sociedade, as quase tem como objetivo apresentar o Sistema de Saúde do Brasil, explicar a complexidade da relação médicopaciente e demonstrar a atuação da equipe multidisciplinar.

O ciclo prático do curso está voltado a ensinar e introduzir as clínicas, emergência, cirurgia. Ele é feito no terceiro e quarto ano do curso, com aulas teóricas e práticas. O internato é o momento em que o aluno tem oportunidade de praticar por meio de estágios supervisionados a prática médica, nos dois últimos anos de curso.

A morte é um fato que estará ligado à rotina médica em quase todas as especialidades. Entendê-la de forma a não se constituir um tabu é de suma importância para a manutenção do médico como profissional e do paciente como indivíduo. Foi evidenciado um despreparo dos estudantes dos quatro primeiros períodos que é justificado pela falta de experiência com o paciente, e com situações que demandem parcela de responsabilidade e comprometimento.

Resultados semelhantes foram encontrados no estudo de Marta et al. ${ }^{(11)}$ que mostrou que no que concerne ao preparo pessoal para lidar com a morte e o processo do morrer, $54 \%$ dos graduandos respondentes da pesquisa se julgaram aptos a enfrentar a circunstância e 46\% disseram que provavelmente ou certamente não estão preparados para a situação.

A grande maioria dos estudantes os quais participaram da pesquisa, afirmaram que na graduação alteraram a sua percepção sobre a morte e o morrer. No entanto, muitas vezes essa mudança pode ter sido sem orientação e acompanhamento, seja pela falta de contato com essa temática dentro da graduação, ou mesmo pela escassez de preparo para lidar com o assunto, dos próprios médicos docentes que os alunos acompanham.

$\mathrm{O}$ reconhecimento do "ser médico" inicia-se no macrocontexto no qual ele está inserido: a sociedade, que por sua vez repercute na formação desses profissionais e no modo como cada um concebe sua história de vida e sua função social. Ao longo do processo histórico, o "ser médico" foi 
personificado como curador, provedor de cuidados, em alguns momentos visto como próximo dos místicos e mágicos, detentor de poderes que os colocavam em um patamar acima dos demais seres humanos. Por conseguinte, tal imaginário, atravessado de idealização, privava a figura do médico de características humanas, como suscetibilidade ao cansaço, à dor e ao sofrimento, prevalecendo a visão de um ser imune à falha ${ }^{(12)}$.

Albertoni et al. ${ }^{(13)}$ analisaram os comportamentos dos estudantes em relação a morte. Evidenciaram que o processo de lidar com pacientes terminais é tido como difícil para os estudantes, sendo percebido que o envolvimento com a morte traz consequências na forma de viver e no futuro profissional dos participantes. Os resultados encontrados encontram-se acordam com esse estudo, mostrando que a maioria dos estudantes afirmou uma mudança na sua atuação após a vivência da morte.

Discussões sobre a terminalidade da vida podem ajudar os acadêmicos a esclarecerem melhor a questão da morte e do morrer. No entanto, Silva e Ayres $^{(14)}$ relatam que as experiências de ensino-aprendizagem em relação a lidar com o paciente perante a morte são bastante escassas, sendo identificado que o tema da morte ou não é trabalhado ou é, até mesmo, evitado. Em relação à participação em discussões sobre a terminalidade da vida, os resultados encontrados corroboram estudos anteriores.

\section{Conclusão}

Pode-se concluir que mesmo sabendo que a morte é um processo natural e comum no cotidiano de um profissional da área de saúde, uma grande parcela dos estudantes de medicina considera-se despreparada para lidar com tal situação. Essa informação se relaciona, em parte, com os alunos do ciclo teórico que ainda não têm tanto contato com pacientes, tendo a sensação de despreparo, pelo fato de estarem no início do curso, e também, por poucas oportunidades de discussões sobre a terminalidade da vida em sala de aula.

Os objetivos gerais e específicos do trabalho foram alcançados, visto que ficou evidente que a morte ainda é um tabu dentro do curso de Medicina, e que a percepção dos futuros médicos é muito superficial e trás, por diversas vezes, mudanças na interpretação de tal fenômeno de forma desorientada. A 
frequência das situações que envolvem a morte e o morrer aumentam de acordo com a evolução dos anos dentro do curso, a qual não está sendo acompanhada por um preparo teórico e didático sobre tais situações.

Nesse processo de formação profissional, no contexto da graduação em Medicina, ressalta-se que a educação formal para morte poderia transformar-se em um espaço de construção de novos sentidos e novas maneiras de intervenção sobre a realidade, além de possibilitar a superação da alienação e um desenvolvimento humano mais pleno.

Dos alunos que tiveram contato com a morte na graduação, a maioria afirmou ter mudado sua visão durante a atuação, como acadêmicos, e muitos deles afirmaram querer conhecer mais o tema e compreender melhor a terminalidade da vida. As Instituições de Ensino Superior devem aprofundar as discussões sobre morte e religião, infância/adolescência, velhice e processo de luto, de forma contextualizada com a realidade a fim de formar médicos preparados para as mais diversas situações advindas da prática profissional.

\section{Referências}

1. Rockembach JV, Casarin ST, Siqueira $\mathrm{HCH}$. Morte pediátrica no cotidiano de trabalho do enfermeiro: sentimentos e estratégias de enfrentamento. Rev. Rene. Fortaleza. 2010; 11(2):63-71.

2. Caputo RF. O homem e suas representações sobre a morte e o morrer: um percurso histórico. Rev. Mutidisciplinar em Saúde. 2008;(6):7380.

3. Santos SF. Ritos funerários na Grécia Antiga: Um espaço feminino. I Congresso Internacional de Religião, Mito e Magia. Universidade do Estado do Rio de Janeiro; 2010.

4. Combinato DS, Queiroz MS. Um estudo sobre a morte: uma análise a partir do método explicativo de Vigotski. Ciência \& Saúde Coletiva. 2011;16(9):3893-900.

5. Silva AM, Silva AJP. A preparação do graduando de enfermagem para abordar o tema morte e doação de órgãos. Rev. Enferm UERJ. 2007;15(4):549-54.

6. Azeredo NSG, Rocha CF, Carvalho PRA. O enfrentamento da morte e do morrer na formação de acadêmicos de medicina. Rev. Brasileira de Educação Médica. 2011;35(1):37-3.

7. Bandeira D, Cogo SB, Hildebrandt LM, Badke MR. A morte e o morrer no processo de formação de enfermeiros sob a ótica de docentes de enfermagem. Texto Contexto Enferm, Florianópolis. 2014; 23(2):400-07.

8. Oliveira WIA, Amorim RC. A morte e o morrer no processo de formação do enfermeiro. Rev. Gaucha Enferm. 2008; 29(2):191-98. 
9. Cantídio FS, Vieira MA, Sena RR. Significado da morte e de morrer para os alunos de enfermagem. Invest. Educ. Enferm. 2011;29(3):407-18.

10. Silva GSN. A construção do "ser médico" e a morte: significados e implicações para a humanização do cuidado. Doutorado [Tese]. São Paulo: Universidade de São Paulo; 2006.

11. Marta GN, Marta SN, Filho AA, Prete JR, Job P. O estudante de Medicina e o médico recém-formado frente à morte e ao morrer. Rev. bras. educ. med., Rio de Janeiro. 2009; 33(3):416-27.

12. Santos MA, Aoki FCOS, Cardoso EAO. Significado da morte para médicos frente à situação de terminalidade de pacientes submetidos ao Transplante de Medula Óssea. Ciência \& Saúde Coletiva. 2013; 18(9):2625-34.

13. Albertoni LI, Jr RS, Cury PM, Pereira PSF, Miyazaki MCOS. Análise qualitativa do impacto da morte sobre os estudantes de medicina da faculdade de medicina de São José do Rio Preto. Arq Ciênc Saúde. São José do Rio Preto. 2013;20(2):49-52.

14. Silva GSN, Ayres JRCM. O encontro com a morte: à procura do mestre Quíron na formação médica. Rev. Bras. Educ. Med. Rio de Janeiro. 2010;34(4):487-96.

15. Camargo AP, Nunes LMF, Reis VKRR, Breschiliare MFP, Morimoto RJ, Moraes WAS. Ensino da morte e do morrer na graduação médica brasileira: revisão de literatura. Rev. Uningá. Paraná. 2015; 25:44-51.
16. Quintanda AM, Rodrigues AT, Arpini DM, Bassi LA, Cecim PS, Santos MS . A angústia na formação do estudante de medicina. Rev. bras. educ. med. Rio de Janeiro. 2008;32(1):7-14. 